\title{
Tingkat Pengetahuan Ibu Balita Tentang Stunting
}

\section{Knowledge Level Of Mothers To Children About Stunting}

\author{
Muzayyaroh \\ Program Studi Kebidanan Fakultas Ilmu Kesehatan Unipdu Jombang \\ Email: yarohmuzay83@gmail.com
}

\begin{abstract}
ABSTRAK
Stunting merupakan kondisi tubuh seorang anak yang terlihat kerdil atau pendek apabila didasarkan pada indek panjang badan menurut umur. Kejadian stunting sangat banyak di temukan pada balita usia 12-36 bulan. Indonesia merupakan negara yang mempunyai kasus stunting ketiga terbanyak seAsia Tenggara. Banyaknya kasus stunting tidak lain akibat dari tingkat pengetahuan orang tua yang kurang memahami tentang stunting. Orang tua khususnya ibu mempunyai peranan yang sangat penting dalam proses tumbuh kembang anak, terutama dalam pemenuhan kebutuhan gizi anak sehingga anak bisa tumbuh dengan baik dan terhindar dari gizi buruk serta stunting. Tujuan dari penenlitian ini adalah untuk mengetahui tentang tingkat pengetahuan dari orang tua yang mempunyai balita tentang sunting. Metode yang digunakan dalam penelitian ini adalah metode deskriptif dengan pengambilan data melalui pengisian kuesioner. Populasi pada penelitian ini adalah semua ibu balita yang sekolah di PAUD Irsyadus Salam sejumlah 35 ibu. Pengambilan sampel dengan jalan non propability sampling dengan tipe purposive sampling. Hasil dari penelitian ini bahwa paling banyak ibu balita yang mempunyai tingkat pengetahuan yang kurang tentang stunting. Dengan adanya penyuluhan tentang stunting diharapakan semua ibu yang mempunyai anak usia balita bisa mencegah terjadinya stunting dan tercapainya kesehatan tumbuh kembang balita secara optimal.
\end{abstract}

Kata kunci : Stunting, Pengetahuan Ibu

\begin{abstract}
Stunting is a condition of a child's body that looks stunted or short if it is based on the body length index according to age. The incidence of stunting is very much found in toddlers aged 12-36 months. Indonesia is a country that has the third highest number of stunting cases in Southeast Asia. The number of stunting cases is nothing but the result of the level of knowledge of parents who do not understand stunting. Parents, especially mothers, have a very important role in the process of child growth and development, especially in meeting the nutritional needs of children so that children can grow well and avoid malnutrition and stunting. The purpose of this research was to find out about the level of knowledge of parents who have toddlers about editing. The method used in this research was descriptive method with data collection through filling out a questionnaire. The population in this study were all mothers of toddlers who attended PAUD Irsyadus Salam with a total of 35 mothers. Sampling by nonprobability sampling with purposive sampling type. The result of this research is that most mothers of toddlers have a low level of knowledge about stunting. With the counseling about stunting, it is hoped that all mothers who have children under five can prevent stunting and achieve optimal health and development of toddlers.
\end{abstract}

Keywords: Stunting, Mother's Knowledge

\section{PENDAHULUAN}

Salah satu masalah kesehatan yang ada di Indonesia dan sangat membutuhkan perhatian serius adalah stunting. Stunting adalah keadaan tubuh kerdil atau pendek atau sangat pendek jika dilihat berdasarkan indek panjang badan atau tinggi badan menurut umur $(\mathrm{PB} / \mathrm{U})$ dengan nilai ambang batas $\mathrm{z}-$ score antara -3 SD sampai <-2 SD, 
sebagai akibat dari kurang gizi dalam waktu yang lama pada masa pertumbuhan dan perkembangan mulai awal kehidupannya. (Kemenkes RI, 2011) (Astari Ld dkk, 2005)

Kejadian stunting lebih banyak dialami pada anak usia 1-3 tahun karena dalam tahapan ini semua yang di butuhkan balita tergantung kepada orang tuanya termasuk dalam pemberian makan dengan baik. Anak dengan kondisi stunting dapat berisiko mengalami terhambatnya proses perkembangan motorik dan mental, produktivitas dan intelektual yang menurun, peningkatan kesakitan dan kematian, peningkatan resiko penyakit degenerative, kegemukan serta beresiko lebih rentan terhadap berbagai penyakit infeksi (Augraheni, 2012).

Menurut WHO 2018, secara universal data prevalensi balita yang terkena stunting pda tahun 2016 sebesar $22,9 \%$ atau sebanyak 154,8 juta balita. Data yang dikumpulkan oleh Word Health Organisasi (WHO) tahun 2018 bahwa prevalensi anak balita yang mengalami stunting diIndonesia termasuk ketiga terbanyak di ASIA Tenggara setelah Timor Leste $(50,5 \%)$ dan India $(38,4 \%)$ yaitu sebanyak $36,4 \%$ (Pusat Data dan Informasi
Kemenkes, 2018). Dengan kata lain bahwa di Indonesai mempunyai angka prevalensi kasus stunting diatas 20\% yang artinya Indonesia belum bisa mencapai target dibawah 20\% yang di targetkan oleh WHO.

Merujuk data EPPGBM (Elektronik Pencatatan dan pelaporan Gizi Berbasis Masyarakat) per tanggal 20 Juli 2019 bahwa provinsi Jawa Timur sendiri mempunyai Prevalensi Stunting pada balita mencapai angka $36,81 \%$. Sedangkan kabupaten jombang penyumbang angka stunting sebanyak $20 \%$. Perlu diketahui target yang diterapkan oleh pemerintah yaitu menurunkan angka prevalensi stunting pada tahun 2018 menjadi 29\% dan tahun 2019 menjadi 28\% dalam Rancangan Pembangunan Jangka Menengah Nasional (RPJMN 20142019) masih belum tercapai. (Pusat Penelitian Badan Keahlian DPR RI, Kementrian Perencanaan Pembangunan Nasional, 2007, Jurnalmojo.com)

Pada tahun 2019 angka prevalensi stunting nasional di Indonesia menurun menjadi 27,67\%. Meskipun terjadi penurunan prosentase prevalensi stunting akan tetapi kasus stunting masih menjadi permasalahan 
Kesehatan yang serius di Indonesia karena angka prevalensi masih di atas prevalensi yang di targetkan oleh WHO yaitu diatas 20\%. Menteri Kesehatan periode sebelumnya mengatakan dan memberikan serta menitipkan kasus stunting kepada menteri yang sekarang untuk terus berupaya untuk menurunkan angka prevalesni stunting di Indonesia menjadi 20\% atas anjuran WHO (Pusat Penelitian Badan Keahlian DPR RI).

Banyaknya kasus stunting yang terjadi di Indonesia membutuhkan perhatian khusus karena jika kasus stunting ini tidak di tangani dengan benar maka akan berdampak pada kualitas sumber daya manusia yang rendah dalam suatu negara. Keadaan stunting juga bisa menyebabkan kemapuan kognitif yang buruk, Produktivitas yang rendah serta meningkatnya resiko penyakit yang dapat mengakibatkan Indonesia mengalami kerugian ekonomi dalam jangka panjang (Kementrian Perencanaan Pembangunan Nasional, 2007).

Menurut WHO, dampak yang ditimbulkan akibat stunting di klasifikasikan menjadi dua kelompok yaitu dampak jangka panjang dan jangka pendek. Dampak jangka panjang yang diakibatkan oleh stunting seperti meningkatnya kesakitan dan kematian, tidak maksimalnya perkembangan kognitif, motorik dan verbal pada anak. Sedangkan dampak jangka pendek dari stunting antara lain postur tubuh yang tidak maksimal sampai dewasa, obesitas, kurangnya konsentrasi saat belajar dan menurunnya produktifitas (Kemenkes, 2018).

Stunting pada balita tidak hanya di sebabkan oleh satu faktor tetapi bisa disebabkan oleh beberapa atau banyak faktor yang saling berhubungan. Pola asuh orang tua meruapakan salah satu faktor yang mempengaruhi kejadian stunting, dimana pola asuh memegang peranan yang sangat penting terhadap terjadinya gangguan pertumbuhan pada anak. Pola asuh yang buruk dapat menyebabkan masalah gizi di masyarakat (UNICEF, 2007).

Beberapa penelitian tentang stunting dimana peneliti menyebutkan bahwa adanya hubungan yang nyata antara pola pengasuhan dengan stunting. Penelitian di Semarang pada anak usia 12 bulan sampai usia 36 bulan menunjukan bahwa status ekonomi keluarga adalah faktor risiko kejadian stunting. Penelitian di Kalimantan Barat menunjukkan bahwa pekerjaan ibu, 
jumlah anggota keluarga dan pendapatan total keluarga merupakan faktor resiko terjdinya stunting pada balita (Demirchyan, dkk 2016; Richard Sa dkk, 2012).

Orang tua terutama ibu mempunyai peranan yang sangat penting dalam pemenuhan kebutuhan zat gizi pada anak karena anak masih menggantungkan segala kebutuhan dan perhatiannya dari orang tua untuk bisa tumbuh dan berkembang dengan pesat dan baik. Pengetahuan yang baik tentang zat gizi sangat dibutuhkan oleh orang tua dalam memenuhi dan menyediakan menu makanan yang baik dan sesuai dengan gizi seimbang dalam tahapan perkembangan anak. Tingkat pengetahuan seseorang bisa mempengaruhi sikap dan prilakunya dalam melakukan berbagai tindakan. Banyaknya kasus stunting dipengaruhi oleh sikap serta pengetahuan orang tua, banyak orang tua balita yang kurang paham dengan apa itu stunting sehingga balita yang mengarah ke stunting tidak segera di lakukan tindakan (Devi N dkk, 2012).

Berbagai upaya sudah di
lakukan oleh pemerintah untuk
mengatasi stunting dengan melakukan
koordinasi lintas sektor, keterlibatan

pemerintah, masyarakat maupun dunia. Pemerintah mengerahkan upayanya lewat intervensi yang spesifik melalui kemenkes, pemeintah provinsi, kebupaten atau kota dan melalui pemberdayaan perempuan (Rosha dkk, 2016).

Menurut Hardiansyah dalam penelitiannya, stunting bisa di cegah melalui pendekatan zat gizi dan non gizi, esensialnnya perbaikan gizi dan status kesehatan pada remaja, calon pengantin wanita, wanita hamil, ibu nifas termasuk anak balita dan anak prasekolah (Rosha dkk, 2016; Hardiansyah, 2017).

Pemberian informasi tentang stunting kepada calon ibu, ibu balita dan pemeberi layanan kesehatan sangat perlu menjadi perhatian supaya bisa mengetahui ciri-ciri dari stunting sehingga dapat di beri intervensi secara maksimal dan kasus stunting bisa di cegah sedini mungkin.

Dalam penelitian maywita 2018, mengatakan bahawa informasi tentang pencegahan kejadian stunting merupakan hal yang sangat krusial bagi kader kesehatan, supaya mereka bisa memberikan penyuluhan kepada ibu-ibu di posyandu dengan harapan kasus stunting bisa menurun. Informasi 
tentang stunting yang telah disampaikan, harusnya orang tua bisa memahami, mencerna dan mengingat dengan baik agar pencegahan stunting dapat dilakukan. Orang tua yang memiliki informasi dan wawasan tentang stunting mempunyai andil yang besar dalam mencegah terjadinya stunting. Sesuai dengan penelitian yang dilakukan rahmawati 2019, bahwa wawasan yang dimiliki oleh orang tua tentang perihal gejala dan efek yang muncul serta cara menanggulangi stunting dapat menjadi penentu sikap orang tua mencegah stunting dan menjaga Kesehatan (Maywita, E, 2018; Rahmawati A, 2019).

Pada saat studi pendahuluan di Play Group Irsyadus Salam pada tanggal 5 januari 2020 ditemukan adanya 1 balita yang mengalami stunting. dan peneliti juga melakukan wawancara sederhana mengenai stunting, ternyata dari $10 \mathrm{ibu}$ balita tidak ada yang tahu apa itu stunting. Penelitian ini bertujuan untuk mengetahui dan mengidentifikasi gambaran tingkat pengetahuan ibu balita tentang stunting.

\section{METODE PENELITIAN}

Dalam penelitian ini metode yang digunakan adalah metode penelitian deskriptif, di mana metode yang diterapkan untuk mengetahui penggambaran atau deskripsi berkenaan dengan kondisi suatu objek yang bisa dibuat (Notoatmodjo, 2012).

Populasi dalam penelitian ini adalah ibu-ibu dari balita yang sekolah di PAUD Irsyadus Salam berjumlah 35 orang. Pengambilan sampel pada penelitin ini dengan jalan non probability sampling dengan tipe purposive sampling, dengan kriteri inklusi ibu yang datang ke paud isyadus salam untuk mengantarkan anaknya sekolah, sehat dan bisa membaca serta berkenan dijadikan responden dan mau mengisi kuesioner yang di berikan peneliti. Kriteria ekslusi dalam penelitian ini yaitu ibu yang tidak datang dan sedang sakit pada saat melakukan pengisian kuesioner. Data dikumpulkan melalui penyebaran kuesioner yang berisi soal tentang stunting. Etika pengambilan data pada penelitian ini dengan melakukan anonymity dimana tidak ada pencantuman identitas dari responden pada lembar kuesioner, confidentiality yaitu menjaga kerahasiaan terkait 


\begin{abstract}
informasi yang diberikan oleh responden, benefiency yaitu adanya manfaat dari penelitian yang di peroleh responden, non maleficence yaitu penelitian yang dilakukan tidak memberikan kerugian kepada responden dan yang terakhir justice yaitu tidak adanya perbedaan perlakuan pada responden yang diberikan oleh peneliti dalam pemberian Tindakan. Penelitian ini dilakukan di PAUD Irsyadus Salam pada tanggal 10 Maret 2020.
\end{abstract}

\section{HASIL DAN PEMBAHASAN}

Peneliti melakukan penelitian di Play Group Irsyadus Salam dengan judul "Tingkat Pengetahuan Ibu Balita tentang Stunting" pada tanggal 5 Januari dan 10 maret 2020 dengan jumlah 35 ibu balita.
Tabel 1. Distribusi Frekuensi Responden

\begin{tabular}{ccc}
\hline Karakteristik & Frekuensi & Persentase \\
\hline Usia ibu & & \\
Dewasa awal & 24 & 68,6 \\
(26-35 tahun) & & \\
Dewasa akhir & 11 & 31,5 \\
(36-45 tahun) & & \\
Pendidikan & & \\
Dasar & 5 & 14,2 \\
SMP & 25 & 71,5 \\
SMA & 4 & 11,5 \\
Perguruan & 1 & 2,8 \\
Tinggi & & \\
Status pekerjaan & & \\
Bekerja & 7 & 20 \\
Tidak bekerja & 28 & 80 \\
Pengethuan & & \\
Baik & - & \\
Cukup & 10 & 28,6 \\
Kurang & 25 & 71,4 \\
\hline
\end{tabular}

Dari tabel diatas dapat diketahui bahwa sebagian besar $71,4 \%$ responden mempunyai pengetahuan yang kurang tentang stunting. Dari karakteristik responden bisa di lihat paling banyak responden berusia dewasa awal yaitu sebanyak $68,6 \%$, Pendidikan responden paling banyak SMP sebanya $71,5 \%$ dan Sebagian besar $80 \%$ responden tidak bekerja.

Melihat hasil yang di peroleh dari pengisian kuesioner didapatkan bahwa ada 25 ibu dari 35 responden yang mempunyai pengetahuan kurang tentang stunting. Dari responden di ketahui jika usia responden rata-rata berada pada usia dewasa awal (26-35 tahun). Di lihat dari latar belakang 
pendidikannya juga Sebagian besar responden berpendidikan setingkat SMP dan banyak dari responden yang tidak bekerja.

Dari penelitian ini terlihat bahwa pengetahuan orang tua khususnya ibu tentang stunting masih sangat kurang. Hal ini bisa diketahui dari pendidikan responden yang hanya sebatas SMP, dimana pendidikan seseorang dapat berpengaruh terhadap penetahuan yang di milikinya.

Nursalam, 2001 mengemukakan bahawa semakin tinggi pendidikan seseorang maka makin mudah dalam menerima informasi sehingga pengetahuan yang dimiliki semakin banyak, sebaliknya pendidikan yang rendah atau kurang akan menghambat perkembangan sikap seseorang terhadap nilai-nilai yang baru di kenal. Proses belajar bisa dioengaruhi oleh pendidikan, sehingga jika pendidikan semakin tinggi maka makin mudah untuk menerima informasi. Seseorang dengan Pendidikan yang tinggi cenderung mudah untuk mendapat dan menerima informasi melalui orang lain maupun dari berbagai media massa. Banyaknya pengetahuan yang diperoleh bergantung dari banyaknya informasi yang didapat (Notoadmodjo, 2003).
Menurut yuneta dkk, 2019, dalam hasil penelitiannya mengatakan bahwa pengetahuan berkaitan erat dengan pendidikan, hal ini bisa diasumsikan bahwa seseorang yang memiliki pendidikan yang tinggi maka akan semakin banyak dan luas pengetahuan yang di milikinya. Jika pengetahuan seseorang baik maka dapat mengetahui sedini mungkin masalah yang sedang dihadapi dan bisa melakukan intervensi yang baik dalam menghadapi masalah. Sama halnya dengan seorang ibu, jika ibu tersebut punya pengetahuan yang baik dan pemahaman yang baik pula tentang masalah stunting maka ibu tersebut akan melakukan pencegahan agar balitanya tidak mengalami stunting dengan melakukan menajemen rumah tangga yang baik misalnya dengan penyediaan yang baik dan sesuai dengan gizi seimbang untuk keluarganya. Ini sesuai dengan penelitian yang sudah dilakukan oleh Aryastami 2019, bahwa ibu yang memiliki kemampuan dalam dirinya sendiri akan meningkatkan pengetahuan yang baik maupun cukup untuk mengatasi upaya pencegahan stunting. Tetapi suatu pengetahuan tidak hanya diperoleh dalam dunia pendidikan saja tetapi bisa di peroleh melalui berbagai 
media informasi seperti adanya penyuluhan, seminar bahkan bisa dari media sosial. Orang tua yang memdapatkan informasi melalui media apapun tentang stunting tentu akan memahami dan menafsirkan serta mengingat pesan yang telah disampaikan sehingga membentuk pengetahuan yang baik. Informasi yang telah didapat bisa memberikan pengaruh pada tingkat pengetahuan seseorang meskipun seseorang mempunyai pendidikan yang rendah, akan tetapi jika ia juga mendapatkan banyak informasi dari berbagai media massa seperti majalan, surat kabar, televisi, radio ataupun lainnya maka hal itu dapat meningkatkan pengetahuan seseorang (Apriadji, 2986).

Dengan pengetahuan yang cukup maka seseorang akan lebih banyak punya rasa keingin tahuan akan suatu hal begitu juga dengan kesehatan dirinya dan keluarganya. Sehingga jika ada hal hal yang belum sesuai dengan pengetahuannya maka seseorang akan mencari tahu dan berkonsultasi dengan seorang ahli sehingga tidak sampai menuju hal yang lebih buruk dan bisa menangani dengan cepat dan tepat.

Pengetahuan seseorang selain di pengaruhi dari latar belakang pendidikan juga bisa di pengaruhi oleh beberapa faktor yaitu usia dan pekerjaan. Usia merupakan indikator yang dimiliki oleh seseorang, dimana dengan semakin bertambahnya usia maka bertambahnya ilmu pengetahuan yang di miliki. Dalam penelitian ini usia responden di bagi menjadi 2 kategori yaitu usia dewasa awal dan usia dewasa akhir. Usia dewasa awal merupakan usia yang produktif untuk membentuk rumah tangga dan siap menerima tanggung jawab menjadi ibu dan mengurus rumah tangga. Dalam usia dewasa awal ini seseorang selalu ingin beradpatasi akan kebiasaan baru serta angan-angan sosial yang baru. Dengan kata lain semakin bertambahnya usia seseorang maka semakin banyak pengalaman dan semakin mengerti serta paham dengan keadaan. Kejadian stunting paling banyak pada anak usia 1-3 tahun dimana anak masih sangat tergantung dengan orang lain terutama kepada orang tuanya dalam hal ini seorang ibu. Seharusnya seorang ibu yang usianya sudah dewasa dan siap untuk memiliki anak harus prepare dengan apa yang sedang dibutuhkan anaknya apalagi anak masih dalam tahapan bertumbuh dan berkembang yang masih sangat membutuhkan 
asupan nutrisi yang seimbang serta stimulus yang baik, sehingga anak bisa tumbuh dengan sehat. Terkadang walapunun usia ibu sudah masuk masa dewasa tetapi karena belum siap dan kurangnya pengetahuan tentang kesehatan anak maka akan bisa menyebabkan masalah pada kesehatan anak. Jadi walapun usia ibu sudah dewasa tetapi pengetahuan yang dimilikinya kurang maka hasil akhirnya akan tidak baik. Itulah mengapa perlunya pendidikan dan pengetahuan yang luas bagi seorang ibu. Dengan Pendidikan dan pengetahuan yang luas maka bisa mencegah lahirnya masalah yang terbentuk akibat ketidak tahuan tentang suatu hal (Insan dan Setyorini, 2019).

Tingginya tingkat pengetahuan seseorang selain di pengaruhi oleh factor usia juga dipengaruhi oleh status pekerjaan. Banyak dari orang tua yang dulunya putus sekolah karena harus bekerja untuk memenuhi kebutuhan hidupnya. Pekerjaan seseorang bisa memberikan dampak positif dan juga dampak negatif. Semakin sibuk seseorang khususnya seorang ibu yang memliki anak balita maka semakin sedikit waktu yang bisa di gunakan untuk memperhatikan keadaan dan kondisi anak. Karena kesibukan dalam bekerja sehingga ibu kadang tidak tahu kalau anaknya mempunyai masalah kesehatan seperti stunting. Picauly dan Magdalena dalam hasil penelitiannya mengatakan bahwa ibu yang bekerja memiliki peluang anaknya mengalami tubuh pendek atau stunting lebih besar dibandingkan ibu yang tidak bekerja (Picauly dkk, 2013).

Menurut Berg, ibu pekerja tidak akan mempunyai cukup banyak waktu dalam memperhatikan makanan anak yang sesuai dengan kebutuhan dan kecukupan serta kurang perhatian dalam pengasuhan anak. Tetapi jika di lihat dari segi positifnya seseorang yang memiliki pekerjaan bisa membuat seseorang bertemu banyak orang dan berbagi pengalaman sehingga mereka bisa belajar dari apa yang pernah dialami temannya dan bisa waspada agar apa yang dialami temanya tidak terjadi pada dirinya. Orang tua khususnya ibu yang bekerja bisa menambah penghasilan sehingga bisa membantu keuangan keluarga dalam memenuhi kebutuhan nutrisi keluarga terutama anak yang masih dalam masa pertumbuhan dan perkembangan sehingga anak tumbuh dengan sehat. Orang tua yang mempunyai pendapatan 
memadai dalam keluarga akan lebih mampu untuk memenuhi semua kebutuhan primer dan sekunder pada anak, juga memiliki akses ke pusat kesehatan yang jauh lebih baik serta cenderung lebih memilih dan mengkonsumsi makanan dalam kuantitas dan kualitas yang bergizi dan bervariasi (Berg A, 1986; Pipes dkk, 1985).

Tingkat pengetahuan saling berkaitan dengan faktor usia dan pekerjaan seseorang. Semakin matang usia seseorang maka semakin banyak pengetahuan dan pengalaman yang di milikinya sehingga mereka akan lebih hati-hati dalam memutuskan segala sesuatu yang berkaitan dengan kehidupannya. Begitu dengan pekerjaan, semakin tinggi posisi pekerjaan seseorang maka cenderung semakin banyak pula pengalaman dan pengetahuan yang dimiliki serta semakin matang cara berpikirnya. Tingkat Pendidikan mempengaruhi tingkat pengetahuan sedangkan tingkat pengetahuan yang tinggi bisa membantu dalam pemilihan makanan dengan tepat dan bijak serta penanganan gangguan kesehatan dengan baik (Huang W, 2015).

\section{SIMPULAN DAN SARAN}

Tingkat pengetahuan ibu tentang stunting masih kurang, hal ini diakibatkan karena usia ibu yang masih belum siap untuk berumah tangga, Pendidikan yang hanya sebatas SMP dan banyaknya yang tidak bekerja sehingga kecukupan akan konsumsi makanan yang bergizi tidak tercapai.

\section{DAFTAR PUSTAKA}

Astari Ld, Nasoetion A \& Dwirini CM. The correlaton between family, child rearing and stunting prevalences among 6-12 months babies. Media Gizi dan Keluarga. 2005; 29:40-46.

Augraheni, Faktor resiko kejadian stunting pada anak usia 12-36 bulan dikecamatan pati (Skripsi). Semarang: Universitas Diponegoro; 2012.

Arsyatami, N.K., \& Tarigan, I. (2017). Kajian Kebijakan dan Penanggulangan Masalah Gizi Stunting Di Indonesia. Buletin Penelitian Kesehatan, 45(4), 233240.

https://doi.org/10.22435/bpk.v45i 4.7465.233-240

Berg A. Peranan Gizi Dalam Pembangunan. Jakarta: Penerbit Rajawali; 1986.

Bunga Ch Rosha, Kencana Sari1, Indri Yunita SP, Nurilah Amalia, N.U. 2016. Peran Intervensi Gizi Spesifik dan Sensitif Dalam Perbaikan Masalah Gizi Balita di Kota Bogor. 127-138. 
Demirchyan, Anahit. Petrosyan, Varduhi. Sargsyan, Viktoria \& Hekimian Kim. Predictors of stunting among children age 0 to 59 months in rural region of Armenia. Journal of pediatric gastroenterology and Nutrition. 2016; 1: 150-156.

Devi N. Gizi anak sekolah. Jakarta: Buku Kompas; 2012.

Huang W. Understanding the effects of education on health: evidence from China. 2015.

Kementrian Kesehatan, Keputusan Mentri Kesehatan Republik Indonesia no:1995/Menkes/SK/XII/2010. Jakarta: Kementrian Kesehatan Republik Indonesia; 2011.

Kementrian Keseshatan Republik Indonesia. 2018. Buletin Stunting. Situasi Balita Pendek (Stunting ) di Indonesia, 301(5), 1163-1178.

Kementrian Perencanaan Pembangunan Nasional/ Badan Perencanaan Pembangunan Nasional. Rencana aksi nasional pangan dan Gizi 2006-2010. Jakarta;2007.

Maywita, E. (2018). Faktor Resiko Penyebab Terjadinya Stunting Pada Balita Umur 12-59 Bulan di Kelurahan Kampung Baru Kec. Lubuk Begulung Tahun 2015. Jurnal Riset Hesti Medan Akper Kesdam I/BB Medan, 3(1), 56. https://doi.org/10.34008/jurhesti.v 3i1.24.
Notoatmodjo, S (2012). Metode Penelitian Kesehatan.

Notoatmodjo, S (2003). Pendidikan dan Perilaku Kesehata. Rineka Cipta. Jakarta.

Picauly I, Magdalena T, Sarci, Analisis Determinan dan Pengaruh Stunting terhadap prestasi belajar anak sekolah di Kupang dan Sumba Timur NTT. Jurnal Gizi dan Pangan. 2013;8(1):55-62.

Pipes LP. Nutrition in infancy and childhood. Missouri: Times Mirror/ Mosby College Publishing: 1985.

Pusat Penelitian Badan Keahlian DPR RI Gd. Nusantara I Lt. 2 Jl. Jend. Gatot Subroto Jakarta Pusat 10270 c 5715409 d 5715245 m infosingkat@gmail.com.

Rahmawati, A (2019). Faktor yang Berhubungan dengan Pengetahuan Orang Tua tentang stunting pada Balita. Jurnal Ners dan Kebidanan (Journal Of ners and Midwifery), 6(3), 389-395. https://doi.org/10.26699/jnk.v6i3. art.p389-395.

Richard Sa, Black Re, Gilman Rh, Guerrant RI, Kang G, Lanata Cf, Molbak K, Rasmussen Za, Sack $\mathrm{Rb}$, Valentiner-Branth $\mathrm{P} \quad$ \& Checkley W. Wasting is associatedwith stunting in early childhood. Journal Of Nutrition. 2012; 142: 1291-1296. 
UNICEF. Progress for children. 2007. http://www.unicef.org/publication
s/files/Progress for Children No 6 revised.pdf. 